\title{
PERSPECTIVES Digital health leadership: carving a new pathway
}

\author{
Author: Sam Shah ${ }^{\mathrm{A}}$
}

\begin{abstract}
Digital health is a novel and emerging field within healthcare, with a professional group that is evolving just as rapidly. In recent years, training opportunities within digital health have become more present in research, the NHS and the private sector. This article offers a personal reflection on a digital health leadership journey and makes the case for flexibility in training and career opportunities. If policy makers and senior leaders want to realise the outcomes from successive workforce reviews, such as The Topol Review, then there is a case for more inclusive digital leadership roles open to the widest range of suitably skilled professionals.
\end{abstract}

KEYWORDS: Digital health, training, leadership, flexible training

DOI: 10.7861/fhj.dig-2020-path

\section{Introduction}

Digital health leadership can, at times, seem like an enigma; this may not be that surprising given the tension between the digital aspects of a role and the more traditional leadership requirements. While there have been a range of development opportunities in recent years, the path to digital leadership for most people in healthcare is often less structured with a combination of life experiences. My own route to digital leadership may not be that different to many others in the sector and combines the experiences gained over a portfolio career, spanning sectors, specialisms and roles.

When I contemplated a clinical career, digital leadership and digital health were not really defined or very well known. It was in the mid-90s, implementing a computer system in an NHS general medical practice and summarising clinical records that I first gained exposure to clinical informatics. At that time information technology (IT) was still the preferred term. My undergraduate clinical education was relatively traditional, as was my specialist training in public health. It was only really when I took up career opportunities outside of mainstream clinical practice that I gained a variety of experiences that better equipped me for a career in digital health.

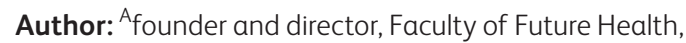
Birmingham, UK

\section{Undergraduate training}

My undergraduate training in dentistry followed a model of medical and dental education that evolved in the 1990s, described as the 'Miller pyramid'. The model set out by George Miller, moved away from the Flexnerian model, which had focused on theoretical knowledge, to a model where assessments were based on clinical performance. ${ }^{1}$ This resulted in undergraduate medical and dental education that offered a much greater focus on clinical performance but little exposure to digital health, technology or health informatics. During my undergraduate training, there was negligible use of digital technology within the clinical setting. Earlier research identified that health informatics teaching within the medical undergraduate curriculum was low and was rarely assessed. ${ }^{2}$ I would argue that dental education, similarly, contained little content on health informatics or digital health. Despite the prominence of technology, most medical and dental schools still have not addressed this gap.

\section{Postgraduate training}

My postgraduate training started off in primary care with vocational training, I had the benefit of working in a practice that was using a small element of digital X-ray and was even contemplating a website. The use of technology involved onthe-job training and an electronic health records system was only introduced towards the end of my training period, despite the significance of clinical safety and information governance in health IT, the concepts of security, privacy were almost entirely absent. ${ }^{3-5}$ Within postgraduate training, the model offered little flexibility for development outside of mainstream clinical topics. The career options that were available at the time were either to continue in general practice or to undertake specialist training. There was little encouragement for exploring anything outside of these two pathways. Complementary career options or alternative training opportunities seemed to be viewed negatively. The model of training was inflexible and rigid, which has been widely commented on. ${ }^{6}$

\section{Research skills}

Having maintained some links to academia from when an undergraduate, I decided to undertake some work as a research assistant, first working on clinical research in the treatment of trigeminal neuralgia and later supporting the scientific validation of pain questionnaires. My first funded research project involved 
the study of mouth cancer in an east London South Asian community. While I had not realised it at the time, this offered a whole range of experiences from managing projects, through to creating data entry tools and improving data quality. It was through this work that I became proficient with analytical and statistical packages that were being increasingly used as well as geographical mapping tools. However, it was the mouth cancer research that highlighted the reality of health inequalities, especially within ethnic minority communities.

\section{Public health}

Having developed an interest in epidemiology and public health, I applied for specialist training in dental public health, which to most dentists may have seemed entirely about counting decayed teeth or discussing water fluoridation, and most medical professionals had not even heard of this specialty. Dental public health was a very small specialty with fewer than a hundred specialists across the UK and poorly integrated into the rest of the public health system. ${ }^{7}$ It was a behavioural scientist who advised me to negotiate a different path, he predicted that this specialty would dwindle but the broader training opportunities would be valuable. My first task in higher training was to negotiate a very different programme, which would involve public health with health economics as well as training placements in rotations outside of my training pathway. Naively, I assumed that the correct process was to complete the various forms with the then Deanery and seek permission from the various committees involved in training, it was my training programme director and lead consultant who secured my chosen approach directly with the post graduate dean.

\section{Non-traditional careers}

The novelty of health economics and health services management, combined with some previous work outside of healthcare, and interacting other postgraduate students, encouraged me to apply for roles outside of the NHS. Having considered the pharmaceutical industry, private healthcare and consulting, I settled on healthcare consulting. The opportunity was one of my better career choices as it provided experience on a range of projects within healthcare across the NHS. It was a supportive environment that offered training but also practical application of analytical and problemsolving skills on a wide variety of projects with everything from advising on commissioning strategies and undertaking needs assessments, through to implementing the Marmot review and due diligence of hospital mergers. The Care Quality Commission had recently formed, as had Monitor, so there were also numerous projects working with regulators and assuring shadow boards of emerging foundation trusts. This opened a window into the world of NHS management, and resulted in successfully taking up a nonexecutive role with an NHS trust. The overwhelming advice at the time from most senior clinicians was that completion of specialist training was advisable for any very senior clinical leadership role.

\section{Fellowships}

Soon after returning to specialist training, the reorganisation of the NHS was beginning with the Lansley reforms, at the same time Darzi fellowships were being expanded with a greater focus on building clinical leadership capacity that offered value to the NHS. ${ }^{8}$ While leadership training in UK healthcare was rapidly evolving with numerous initiatives, most of these programmes were ring fenced for medical professionals and were not generally open to other healthcare professionals. Job descriptions and applications were, in most cases, designed only for General Medical Council registrants with little opportunity for others. At the same, there were multiple challenges for eligible medical applicants to take time out of training, often struggling to gain senior support or sponsorship. After some negotiation, I managed to apply and take up a Darzi Fellowship in leadership for clinical commissioning. ${ }^{9}$ This was novel for my trainers as they had to work out how to count time in training for a split role and I had to learn how to balance public health commitments with clinical commissioning responsibilities.

The difficulty with certain programmes where post holders are splitting their time between more than one role is that there is rarely any reduction in workload. Those undertaking such programmes, ie part-time fellowships or part time PhDs, can end up carrying out a full-time role over fewer days as well as participating in a fellowship or academic programme.

The fellowship year changed the course of my career both in terms of public health but also started projecting a course into technology. During the year, I was involved in a number of projects but three in particular came about at the same time, the first being to digitise referrals from primary care dentistry to hospital services; the second to provide clinical leadership in the implementation of NHS 111 in north London and the third was commissioning a health systems integration engine. All of these projects immersed me in digital health within the NHS and provided a new way of utilising a range of skills gained from clinical practice, public health and management consulting.

\section{Clinical leadership}

Completing both specialist training and a Darzi Fellowship, opened up the opportunities to move into clinical leadership and embrace a portfolio career. This came about in a number of ways but mainly taking up a training programme director role, honorary consultant appointment and a clinical leadership role with some NHS clinical commissioning groups. However, the main drawback was the inability to combine a substantive career in my chosen specialty with a portfolio career. It did at times seem like having a certificate of completion of training was perceived to be more important than the type of experience gained.

\section{Digital leadership}

After leading on some national digital transformation programmes, I joined the first cohort of the NHS Digital Academy, very much seen as a way of bridging the gap between clinical informatics and data science. ${ }^{10}$ Digital health in the UK includes a supportive and inclusive community that spans professional boundaries, roles and sectors. There seems to be greater acceptance of the mixed economy between the private sector and the public sector with people moving between the two. Having worked with a number of digital leaders in the NHS but also in other sectors, it seems clear that there are multiple routes to arriving at a similar end point.

\section{Conclusion}

Compared with where my career started and my first exposure to health informatics, digital health as an emerging field becoming 
increasingly more structured and organised. However, despite the structure, the limited training pathways, the absence of undergraduate training and inflexibility in postgraduate training may result in relatively few clinicians pursuing a career in digital health. ${ }^{11}$

Fellowships offer multiple benefits; however, they still seem to be open to a minority of healthcare professionals, and lack of funding seems to be further constraining these schemes. ${ }^{12}$ Chief clinical information officer roles may seem inaccessible to many clinicians other than medical professionals, as new roles emerge, such as chief research information officers, executives need to ensure all these digital roles are accessible to the broadest group of applicants. ${ }^{13}$

The opportunities afforded to me over my career have helped progress my digital leadership journey and maximise what I was able to offer to the health system. Broader public health training and the Darzi clinical leadership fellowship resulted in a move into clinical leadership which in turn led to a digital health career. Postgraduate training generally neglects the expected standards of health informatics training and, on its own, would have been insufficient. $^{14}$

If the government, policy makers and senior leaders are serious about supporting digital health leadership, then they will need to bring about changes to undergraduate training and also open career opportunities to the widest group of health workers. NHS hiring managers and recruiters will also need to take a broader view and that may mean recruiting people based on their digital health skills and not simply because a clinical informatics role may suit a job plan. As a system we need to broaden our appreciation of digital health leadership accepting that digital leaders will come from a range of backgrounds and may not follow a traditional path but one that may still offer significant value.

\section{References}

1 Miller GE. The assessment of clinical skills/competence/performance. Acad Med 1990;65(9 Suppl):S63-7.
2 Walpole S, Taylor P, Banerjee A. Health informatics in UK Medical Education: an online survey of current practice. JRSM Open 2016;8: 2054270416682674.

3 Magrabi F, Baker M, Sinha I et al. Clinical safety of England's national programme for IT: a retrospective analysis of all reported safety events 2005 to 2011. Int J Med Inform 2015;84:198-206.

4 Huston JL. Information governance standards for managing e-health information. J Telemed Telecare 2005;11(Suppl 2):S56-8.

5 Becker MY. Information governance in NHS's NPfIT: a case for policy specification. Int J Med Inform 2007;76:432-7.

6 Goldberg I. Postgraduate medical education and flexible training. Br J Hosp Med. 1996;56:241-2.

7 Lomazzi M, Wordley V, Bedi R. Dental public health capacity worldwide: Results of a global survey. J Public Health Policy 2016;37: 528-42.

8 Malby R, Mervyn K, Boyle TJ. Darzi Clinical Leadership Fellows: an activity theory perspective. J Health Organ Manag 2018;32:793808.

9 Shaw V. Primary care: 'Darzi' fellowship gives boost to commissioning. Health Serv J 2013;123:19-20.

10 Scott P, Dunscombe R, Evans D, Mukherjee M, Wyatt J. Learning health systems need to bridge the 'two cultures' of clinical informatics and data science. J Innov Health Inform 2018;25:126-31.

11 Stagnell S, Patel N, Shah S. Is less-than-full-time training in dentistry swimming against the tide? Br Dent ] 2019;227:347-51.

12 Kyratsis Y, Armit K, Zyada A, Lees P. Medical leadership and management in the United Kingdom. Australas Psychiatry 2016;24: 240-2.

13 Sridharan S, Priestman W, Sebire NJ. Chief Information Officer team evolution in university hospitals: interaction of the three ' $C$ 's (CIO, CCIO, CRIO). J Innov Health Inform 2018;25:88-91.

14 Jidkov L, Alexander M, Bark $P$ et al. Health informatics competencies in postgraduate medical education and training in the UK: a mixed methods study. BMJ Open 2019;9:e025460.

Address for correspondence: Prof Sam Shah, Faculty of Future Health, College of Medicine and Dentistry, 32-34 Colmore Circus, Birmingham B4 6BN, UK.

Email:sam.shah@nhs.net 